\title{
Morphological Characterization of Finger Millet Germplasm Collected from Uttrakhand Hills for Qualitative Traits
}

\author{
Ankit Kumar*, H. S. Chawla, A. S. Jeena and Rohit \\ Department of Genetics \& Plant Breeding, G. B. Pant University of Agriculture \& \\ Technology, Pantnagar, India \\ *Corresponding author
}

\section{Keywords}

Finger millet, germplasm, qualitative traits.

Article Info

20 August 2019 Available Online: 10 September 2019

\section{A B S T R A C T}

The preset investigation was consisted of evaluation of 92 finger millet accessions for qualitative morphological descriptors at Pantnagar Centre for Plant Genetic Resource, G.B. Pant University of Agriculture and Technology, Pantnagar. Observations were recorded for sixteen qualitative characters on visual basis at different stages of development, as per DUS guidelines standardized by PPV\&FR. Out of 92 accessions, most of the accessions exhibited erect growth (50\%), droopy ears $(27.14 \%)$, dark green glume $(58.70 \%)$, non-pigmented leaf juncture $(67.30 \%)$, non-pubescent leaf sheath (33.69\%), non-culm stem branching $(67.39 \%)$ and lodging susceptibility (55.44\%). Majority of germplasm entries exhibited nonbranched fingers $(88.40 \%)$ with multiple whorls $(91.30 \%)$, among branched fingers predominance $(63.04 \%)$ was for in thumb position. Seeds of majority of genotypes had enclosed glume cover $(58.69 \%)$, brown color $(55.43 \%)$, round shape $(42.39 \%)$, rough surface $(52.17 \%)$, un-persistent pericarp $(76.08 \%)$ with shattering nature $(60.87 \%)$.

\section{Introduction}

Finger millet or ragi (Eleusine coracana L. Gaertn.), is a food crop which is mainly cultivated in arid and semi-arid regions of the world and occupies unique position in agriculture due to its high nutritional value and higher adaptability to various environmental conditions. It shows adaptability to diverse agro ecological zones, higher elevations, dry and rained conditions better than any other tropical cereal. It is principally grown by small-holder farmers and is often regarded as a poor man's food. Finger millet seeds are rich source of carbohydrates $(65-70 \%)$, dietary fibers $(2.5-3.5 \%)$, fat (1$1.5 \%)$, minerals $(2.5-3 \%)$ and proteins $(5-8 \%)$.

Moreover, its proteins are rich inessential amino acids namely, tryptophan, threonine, 
lysine, methionine, valine and isoleucine (FAO, 1991). The crop is also reported to have hypoglycemic, hypocholestrolemic and antiulcerative properties (Panwar et al., 2010). Because of such attributes, finger millet has been promoted as part of a solution to malnutrition (Singh and Raghuvanshi, 2012).

In finger millet and most related wild species, morphological descriptors that include attributes, characteristics, or measurable traits observed in an accession have been greatly used in diversity studies.

The descriptors in finger millet germplasm characterization include qualitative and quantitative traits. Qualitative traits which were recorded on the basis of visual assessment plays important role in racial differentiation and varietal identification.

\section{Materials and Methods}

The present investigation was consisted of evaluation of 92 finger millet accessions for qualitative morphological descriptors at Pantnagar Centre for Plant Genetic Resource, G.B. Pant University of Agriculture and Technology, Pantnagar.

The experiment was laid out in augmented block design-II with four blocks. Each block consisted of twenty- eight rows intervened by the five checks VL 315, VL 149, VL 324, PRM 1 and PRM 2 placed randomly within each block.

Observations were recorded for sixteen qualitative characters viz., plant growth habit, pigmentation at leaf juncture, leaf sheath pubescence, glume color, stem culm branching, ear shape, finger branching, position of branching in finger, finger multiple whorl, seed shattering, seed covering by glume, seed color, seed shape, seed surface, pericarp persistence after harvesting and lodging resistance. All these observations were taken on visual basis at different stages of development, as per DUS guidelines standardized by PPV\&FR.

\section{Results and Discussion}

Visual assessment of 92 finger millet germplasm accessions was done for all the 16 qualitative traitsasfurnishedinTable1.

Out of 92 observed accessions, decumbent growth habit was exhibited by $32.58 \%$ entries, while remaining $50 \%$ and $17.39 \%$ accessions have shown erect and prostrate growth habit respectively. Leaf juncture of only $33.70 \%$ germplasm entries, including GP-2016-117, GP-2016-120, GP-2016-131, GP-2016-132, GP-2016-140, GP-2016-147, GP-2016-187, GP-2016-190, GP-2016-193, etc. have shown pigmented leaf juncture, while leaf junctures of rest of the entries were found to be unpigmented. Leaf sheath pubescence is an important feature of crop plants which attributes towards water and heat tolerance through lowering down the canopy temperature.

Among presently evaluated entries, genotypes with pubescent leaf sheath were the dominant $(66.31 \%)$ ones, followed by the nonpubescent (33.69 \%) genotypes. Out of different variation for glume coloration, dark green was dominant $(58.70 \%)$, followed by light purple $(28.26 \%)$ and dark purple (13.04 $\%)$. However, none of the entries were found to be white or light green for glume color. Stem Culm branching is an essential trait which also contributes toward lodging resistance during maturity. Culm branching of stem was present only in $32.61 \%$ of germplasm entries. Ear shape is an essential yield contributing trait with some of its role in sub-race identification. Among all the studied entries, entries with droopy type ears were prominent $(27.14 \%)$, preceded by entries with semi compact $(23.91 \%)$, open $(22.82 \%)$ and first type $(26.13 \%)$ ear shapes. 


\begin{tabular}{|c|c|c|c|}
\hline S.N & & & \\
\hline & Chal acter & Ciass & \\
\hline \multirow[t]{3}{*}{1} & \multirow[t]{3}{*}{ Plant growth habit } & Erect & 47 \\
\hline & & Decumbent & 30 \\
\hline & & Prostrate & 15 \\
\hline \multirow[t]{2}{*}{2} & \multirow{2}{*}{$\begin{array}{l}\text { Pigmentation at leaf } \\
\text { juncture }\end{array}$} & Absent & 61 \\
\hline & & Present & 31 \\
\hline \multirow[t]{2}{*}{3} & \multirow[t]{2}{*}{ Leaf sheath pubescence } & Absent & 31 \\
\hline & & Present & 61 \\
\hline \multirow[t]{3}{*}{4} & \multirow[t]{3}{*}{ Glume color } & Dark Green & 54 \\
\hline & & Dark Purple & 12 \\
\hline & & Light Purple & 26 \\
\hline \multirow[t]{2}{*}{5} & \multirow[t]{2}{*}{ Stem culm branching } & Absent & 62 \\
\hline & & Present & 30 \\
\hline \multirow[t]{5}{*}{6} & \multirow[t]{5}{*}{ Ear shape } & First Type & 13 \\
\hline & & Compact & 11 \\
\hline & & Semi-compact & 22 \\
\hline & & Droopy & 25 \\
\hline & & Open & 21 \\
\hline \multirow[t]{2}{*}{7} & \multirow[t]{2}{*}{ Finger branching } & Absent & 82 \\
\hline & & Present & 10 \\
\hline \multirow[t]{2}{*}{8} & \multirow[t]{2}{*}{ Finger position of branching } & Finger & 34 \\
\hline & & Thumb & 58 \\
\hline \multirow[t]{2}{*}{9} & \multirow[t]{2}{*}{ Finger multiple whorl } & Absent & 8 \\
\hline & & Present & 84 \\
\hline \multirow[t]{2}{*}{10} & \multirow[t]{2}{*}{ Sheet shattering } & Absent & 36 \\
\hline & & Present & 56 \\
\hline \multirow[t]{3}{*}{11} & \multirow[t]{3}{*}{ Seed covering by glume } & Enclosed & 54 \\
\hline & & Exposed & 12 \\
\hline & & Intermediate & 26 \\
\hline \multirow[t]{3}{*}{12} & \multirow[t]{3}{*}{ Seed color } & Copper Brown & 27 \\
\hline & & Dark Brown & 14 \\
\hline & & Light Brown & 51 \\
\hline \multirow[t]{3}{*}{13} & Seed shape & Round & 39 \\
\hline & & Reniform & 30 \\
\hline & & Ovoid & 23 \\
\hline 14 & Seed surface & Rough & 48 \\
\hline & & Smooth & 44 \\
\hline 15 & Pericarp persistence after & Persistent & 22 \\
\hline & threshing & Non-Persistent & 70 \\
\hline 16 & Lodging Resistance & Resistance & 19 \\
\hline & & Moderately Resistance & 12 \\
\hline & & Susceptible & 61 \\
\hline
\end{tabular}


For finger branching, the accessions were grouped as absent and present. Only $21.94 \%$ of accessions viz., GP-2016-122, GP-2016143, GP-2016-194, GP-2016-198, GP-2016200, GP-2017-275, GP-2017-527, GP-2017579, GP-2017-674 and GP-2017-705 have recorded profuse finger branching, while rest of the entries found to bear non-branched fingers. Out of total, $63.04 \%$ germplasm accessions had shown in thumb finger branching, while rest $36.94 \%$ entries has exhibited in all the fingers branching. This trait could also be considered as yield attributing character. Except, GP-2016-122, GP-2016-189, GP-2016-191， GP-2016-198, GP-2016-200, GP-2016-272， GP-2017-527 and GP-2017-705, all other entries (91.30\%) exhibited the presence of multiple whorls in finger.Seed shattering is an important trait for harvesting point of view, non-shattered entries would be more desirable. Out of totalonly $39.13 \%$ entries were non-shattering.Based on seed covering by glumes, genotypes could be classified as enclosed, intermediate and exposed. Most of the genotypes (58.69 \%) were found to be enclosed, whereas intermediate and exposed glume coverings were reported in $13.04 \%$ and $28.26 \%$ of the accessions respectively. Seed color is most important trait in morphological identification, quality determination and cultivars acceptance. None of the entries were found to have white seeds, whereas entries with light brown seeds were most dominant $(55.43 \%)$ followed by copper brown $(28.26 \%)$ and dark brown (16.30 \%).Seed shape is another economic trait. On the basis of seed shape germplasm entries could be grouped into round, reniform and ovoid. Majority (42.39 $\%$ ) of finger millet accessions produced round shaped seeds, followed by (32.61\%) reniform and ovoid (25\%). Round shaped seeds have higher preferences and acceptance as compared to other shapes. Entries with rough and smooth surfaced seeds have almost equal proportion of $52.18 \%$ and $47.82 \%$ respectively. Smooth surface seeds have higher preferences than rough surfaced seeds. For pericarp persistence after harvesting, nonpersistent types were observed to be dominant, as they cover major $(76.08 \%)$ of total population. Resistance to lodging is an important trait which depends upon plant height and various environmental factors. On the basis of lodging resistance genotypes could be classified into three groups, resistance, moderately resistance and susceptible. Majority of germplasm entries $(55.44 \%)$ were observed to be lodging susceptible, followed by lodging resistance $(30.43 \%)$ and moderately resistance (14.13 $\%)$.

Characterization based on visual morphological traits was proved to be quick and effective approach, which demands less time and money even in case of large number of accessions. Bezaweletaw et al., (2007), Reddyet al., (2009), Malambane et al., (2015), Bisht et al., (2015) and Patil et al., (2019)have been performed similar studies.

\section{References}

Bezaweletaw, K., Sripichitt, P., Wongai,W.andHongtrakul,V.2007.Phe notypic diversity of Ethiopian fingermillet [Eleusine coracana (L.)Gaertn] in relation to geographicregions as an aid to germplasmcollection and conservation. KasetsartJournal of Natural Science, 41:7-14.

Bisht, A., Jeena, A.S., Singh, N.K. and Singh, S.P. 2015. Morphological characterization and genetic analysis of finger millet (Eleusine coracana (L.) Gaertn) germplasm. Frontiers in Crop Improvement Journal, 3(1): 9-14.

FAO, 1998. The State of World Plant Genetic Resource for Food Agriculture. FAO Publication. Rome. 
Malambane1, G., Jaisil, P. 2015.Morphological variability for qualitative and quantitative traits in finger millet (Eleusine coracana $\mathrm{L}$. Gaertn). Journal of Advances In Agriculture, 5(1):525-537.

Panwar, P., Saini, R.K., Sharma, N., Yadav, D. and Kumar, A. 2010. Efficiency of RAPD, SSR and cytochrome P450 gene-based markers in accessing genetic variability amongst finger millet (Eleusine coracana) accessions. Molecular Biology Reports, 37(8): 4075-4082.

Patil, S., Kauthale,V., Aagale, S., Pawar, M. and Nalawade, A. 2019. Evaluation of finger millet [Eleusine coracana (L.) Gaertn.] accessions using agromorphological characters. Indian Journal of Agricultural Research, 53(2):120-124.

Reddy, V.G., Upadhyaya, H.D., Godwa, C.L.L, Singh, S., 2009. Characterization of eastern African finger millet germplasm for qualitative and quantitative characters at ICRISAT.SAT e Journal,7(1):1-9.

Singh, P. and Raghuvanshi, R.S. 2012. Finger millet for food and nutritional security. African Journal of Food Science, 6(4): 77-85.

\section{How to cite this article:}

Ankit Kumar, H. S. Chawla, A. S. Jeena and Rohit 2019. Morphological Characterization of Finger Millet Germplasm Collected from Uttrakhand Hills for Qualitative Traits. Int.J.Curr.Microbiol.App.Sci. 8(09): 2105-2109. doi: https://doi.org/10.20546/ijcmas.2019.809.243 